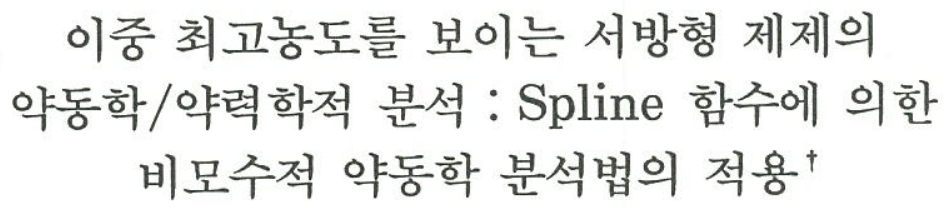

서울대학교 의과대학 약리학교실, 예방의학교실', 서울대학교병원 약제부 ${ }^{2}$ 및 서울대학교병원 임상약리실

유경상, 배균섭, 장인진, 신상구, 조수헌 ${ }^{1)}$, 신완균 ${ }^{2)}$

$=$ Abstract $=$

\title{
Nonparametric PK/PD Analysis of Controlled-Release Formulations Showing Double Peak Concentrations : Application of the Spline Function
}

Ky ung-Sang Yu, M.D., Ky un-Seop Bae, M.D., In-Jin Jang, M.D., Sang-Goo Shin, M.D., Soo-Hun Cho, M.D., ${ }^{1)}$ Wan-Gyoon Shin, Ph.D. ${ }^{2)}$

Department of Pharmacology, Preventive Medicine ${ }^{1)}$, Seoul National University College of Medicine, Department of Pharmacy ${ }^{2}$, Seoul National University Hospital, and Clinical Pharmacology Unit, SNU Hospital

Background : We tried to develop a PK/PD analysis method using the spline function and mixed effect modeling, applicable to drug formulations showing atypical pharmacokinetic behavior such as $\mathrm{CR}$ formulations with double peak concentrations.

Methods: For this purpose, investigational diltiazem CR formulations with different characteristics were administered to 12 healthy volunteers by a crossover design. Plasma concentrations and EKG changes were measured up to 48 hours after administration. Diltiazem plasma concentrations were measured by HPLC. PQ and QT intervals on EKG lead II were analyzed by EKG analysis software. Pharmacokinetic parameters were calculated using the spline function and compared with those obtained by the trapezoidal rule; pharmacodynamic parameters were estimated nonparametrically by mixed-effect modeling using a direct link model.

Results : After administration of $90 \mathrm{mg}$ formulations, the plasma concentration-time curve demonstrated a single peak at 3 hours after administration and a monophasic decay pattern thereafter; after $180 \mathrm{mg}$ formulations two peaks, one immediately after administration and another at 8 hours after administration, were noted.

$\dagger$ 본 연구는 서울대학교병원 지정진료 공동연구비 지원(97년도)에 의하여 이루어졌음. 교신저자: 신상구

소 속:서울대학교 의과대학 약리학교실 및 서울대학교병원 임상약리실

연락주소 : 서울특별시 종로구 연건동 28 (우 110-799)

전 화 : 02)740-8286, Fax:02)745-7996 
- K.S. Yu, et al. : Nonparametric PK/PD analysis of controlled-release formulations showing double peak concentrations -

Pharmacokinetic parameters obtained using the spline function were similar to those calculated using the trapezoidal rule. A linear pharmacodynamic model was used for mixed-effect modeling between plasma concentrations and PQ intervals in the $180 \mathrm{mg}$ group ; the results were $\mathrm{keo}=4.47 \mathrm{hr}^{-1}$, slope $=0.0792 \mathrm{msec} \cdot \mathrm{ml} / \mathrm{ng}$, and intercept $=0.358 \mathrm{msec}$.

Conclusion : The spline function and nonparametric modeling can be applied to PK/PD analyses for formulations such as controlled-release formulations, patch formulations, drugs with a great pharmacokinetic variability, and population PK/PD modeling.

KEY WORDS : Diltiazem · Controlled-release $\cdot$ Spline $\cdot$ Mixed-effect modeling $\cdot$ Pharmacokinetics.

\section{서 론}

일반적인 약물의 약동학/약력학 분석에는 compartment model을 이용한 modeling이나 단순한 noncompartment model 등이 이용되고, 제형간의 비교에는 최고혈장농도 $(\mathrm{Cmax})$, 최고혈장농도 도달 시간(Tmax), 시간-농도곡선하 면적(AUC) 등의 파 라미터가 흔히 이용된다. 그러나 약물의 흡수속도를 지연시킴으로써 최고혈장농도를 낮추고 약물농도의 감소속도를 둔화시켜 약물농도의 fluctuation을 줄일 뿐만 아니라 경우에 따라서는 약물의 투여 횟수도 줄 일 수 있도록 개발된 일부 서방형 제제에서는, 투여 직후의 빠른 약물농도 증가와 이후의 서방으로 인한 일정농도 유지를 목적으로 두 개 이상의 방출 분희 (release portion)을 가지고 있다 ${ }^{1)}$. 이러한 제형의 경우 시간-혈중 농도 곡선은 둘 이상의 peak를 보이 므로 약동학적 분석시 단순한 compartment model, 또는 생물학적 동등성의 비교에 이용되는 단순한 noncompartment model을 적용하면 최고농도, 최고 농도시간 등의 결정에 한계가 있으며, 약동학/약력학 modeling에도 어려움이 따른다. 따라서 본 연구에서 는 반감기가 짧은 칼슘차단제인 diltiazem을 원형 약 물로 이용하여 이러한 다중 peak 농도를 보이는 약물 의 약동학 분석에 필요한 spline 함수 및 mixed effect model을 이용한 nonparametric 약동학/약력학 modeling을 검토하고자 하였다. 이를 위하여 서로 다 른 특성을 가진 diltiazem 서방형 제형 2 가지를 12
인의 피험자에게 투여한 후 48 시간까지 채혈하여 약 물농도를 측정하였고, 측정된 농도 자료 및 심전도 측 정으로 얻어진 약력학 자료로부터 spline 함수와 mixed effect model을 이용한 약동학/약력학적 분석 방법을 검토하였다.

\section{연구 대상 및 방법}

\section{1. 연구 대상}

특별한 병력이 없고 평소 다른 약물을 복용하지 않 는 20 40세의 건강한 성인을 대상으로 모집한 자원 자 중 문진, 이학적 검사, 심전도 검사, 일반혈액 검 사, 일반화학 검사, 요 검사 등을 실시하여 정상적인 심장, 간장 및 신장 기능 등을 가지고 있다고 판단된 12 명 (남자 6명, 여자 6명)을 대상으로 하였다. 이들 은 시험개시 전 설명서를 받고 본 연구에 대하여 충분 히 설명을 들은 후 자의로 참여 여부를 결정하였다. 이들의 평균 연령은 26.9 세(표준편차 3.1 ), 평균 신 장은 $166.4 \mathrm{~cm}$ (표준편차 5.2 ), 평균 체중은 $57.3 \mathrm{~kg}$ (표준편차 6.8)이었으며, 시험 개시 전 1 주 이내에 다른 약물을 복용하지 않았다.

본 연구는 연구계흭 및 동의 취득 등에 관하여 서울 대학교 병원 임상시험 심사위원회(IRB)의 승인을 받 은 후 시행되었고, $\mathrm{KGCP}$ 규정을 준수하여 수행되었 으며, IRB 승인 양식으로 모든 피험자에게 설명 후 서면 동의를 받았다. 
- 유경상 등 : 이중 최고농도를 보이는 서방형 제제의 비모수적 약동학/약력학적 분석 -

\section{2. 투약 및 채혈}

피험자 12 명을 둘로 나누어 6 명씩 진행하였으며, 각 피험자에게 첫날 아침 시험 제형(diltiazem 서방 형 캡슐) $90 \mathrm{mg}$ 을 1 희 경구 투여한 후 48 시간 동안 정해진 일정에 의하여 채혈 및 심전도 측정을 하였고, 투약일 기준으로 1 주 후에 다시 시험 제형 $180 \mathrm{mg}$ 캡슐을 1 회 투여한 후 같은 방법으로 시험을 진행하 였다.

피험자들은 투약 전날 오후 10 시부터 다음날 투약 후 4시간까지 공복 상태를 유지하였으며 투약 후 24 시간 동안 카페인이나 알콜을 함유하는 음료의 섭취를 금하였다. 약은 $200 \mathrm{ml}$ 의 물과 함께 복용하였고 투약 2 시간 후에 $150 \mathrm{ml}$ 의 물을 섭취하도록 하였으며 투약 4 시간 후에 점심 식사를 제공하였다.

채혈은 상박부에 거치한 heparin-locked(100 unit $/ \mathrm{ml}$ ) 정맥내 카테터로부터 시행하였으며, 투약 직전 대조 혈액 $10 \mathrm{ml}$ 를 취하고 투약 후 $0.5,1,2,3,4,6$, $8,10,12,14,24,34,48$ 시간에 각각 $7 \mathrm{ml}$ 의 혈액을 채취하였다. 채혈액은 15 분간 냉장 상태로 방치한 다 음 $3000 \mathrm{rpm}$ 에서 15 분 동안 원심분리하여 혈장을 분 리한 후 약물 농도 측정시까지 $-20^{\circ} \mathrm{C}$ 에서 냉동 보관 하였다.

\section{3. 심전도 측정}

심전도 측정은 투약 전 기저치 및 투약 후 $2,4,6$, $8,10,12,14,24$ 시간에 각각 $\mathrm{PQ}$ 간격, $\mathrm{QT}$ 간격 및 심박수를 측정하였다. 심전도(EKG) monitor를 $\mathrm{AD}$ (analog-digital) 변환기로 컴퓨터에 연결하여 lead II 에서 심전도 분석 프로그램을 이용하여 측정 하였고, 각각 3 개 이상의 파형에서 기록하여 평균을 취하였으며, $\mathrm{QT}$ 간격은 QoT(QRS군의 시작점에서 $\mathrm{T}$ 파의 시작점까지), $\mathrm{QaT}(\mathrm{QRS}$ 군의 시작점에서 $\mathrm{T}$ 파 의 정점까지), $\mathrm{QeT}(\mathrm{QRS}$ 군의 시작점에서 $\mathrm{T}$ 파의 끝 점까지)의 3 가지를 측정하였다 ${ }^{2)}$.

심전도에서 QT 간격은 약물에 의한 영향 이외에도 심박수, 자율신경계 활성도, 측정 방법 등에 의하여
변하며, 이 중 심박수의 영향을 가장 크게 받는다 ${ }^{3.4)}$. 따라서 diltiazem에 의한 QT 간격의 변화를 관찰하 려면 심박수에 의한 영향을 보정하는 것이 필요하며, 여러 가지의 공식들을 이용한 방법들이 보고되어 있으 나, 개개인의 파라미터를 구하지 않는 경우에는 단순 Bazett 방법 이외의 방법들이 뚜렷하게 우월한 점이 없으므로 ${ }^{5)}$ 본 연구에서는 다음과 같이 Bazett 공식 을 사용하였다.

$$
\mathrm{QTc} \text { 간격 }=\mathrm{QT} \text { 간격 } / \sqrt{R R \text { 간격 }[\mathrm{sec}]}
$$

\section{4. 혈장 diltiazem 농도 측정}

혈장 diltiazem 농도의 측정은 역상(reverse phase) HPLC(high-performance liquid chromatography)법으로 측정하였으며, 고정상은 직경 $5 \mu \mathrm{m}$ 의 $\mathrm{C}_{18}$ microsphere로 충전된 Waters Nova-Pak ${ }^{\circledR}$ $(3.9 \times 150 \mathrm{~mm})$ column을 이용하였고, 이동상은 $60 \mathrm{mM} \mathrm{KH}_{2} \mathrm{PO}_{4}$ 와 acetonitrile $\left(\mathrm{CH}_{3} \mathrm{CN}\right)$ 의 $70: 30$ ( $\mathrm{vol}: \mathrm{vol}$ ) 혼합액에 triethylamine을 $5 \mathrm{mM}$ 되도록 가하여 $\mathrm{pH} 4.0$ 으로 조정하여 사용하였다. Diltiazem 을 $237 \mathrm{~nm}$ 에서 자외선 검출기(UV detector)로 검출 하였고 농도는 peak height ratio에 의하여 표준검량 선(standard curve)에서 산출하였다. Pump는 Gil$\operatorname{son}^{\otimes} 302$ 를 flow rate $=1.0 \mathrm{ml} / \mathrm{min}$ 으로 하여 사용하 였으며, 검출기는 Gilson ${ }^{\circledR} 118$ UV/VIS 검출기를 사 용하였다. 혈장 diltiazem 농도의 측정을 위한 내부 표준물질(internal standard)로는 diphenhydramine $\mathrm{HCl}$ 을 사용하였으며 혈장 $2 \mathrm{ml}$ 를 내부 표준물 질 $0.1 \mathrm{ml}$ 및 carbonate 완충액 $(\mathrm{pH} 9.0) 0.1 \mathrm{ml}$ 와 함께 $4 \mathrm{ml}$ 의 추출용매(hexane: isoamylalcohol= $98: 2$ )로 추출한 후 $0.01 \mathrm{M} \mathrm{HCl} 0.15 \mathrm{ml}$ 를 유기용 매층에 넣고 원심분리한 다음 유기용매층을 제거하고 $35 \mu \ell$ 의 수용액 층을 HPLC injector(Rheodyne ${ }^{\text {()) }}$ 에 주입하여 측정하였닿.

\section{5. 약동학/약력학적 분석}

제형에 따른 약동학적 특성은 우선 기존 일반 제형 
- K.S. Yu, et al. : Nonparametric PK/PD analysis of controlled-release formulations showing double peak concentrations -

의 생물학적 동등성 검정에서 사용되는 파라미터인 농 도-시간 곡선하 면적( $\mathrm{AUC})$, 최고 농도( $\mathrm{Cmax})$, 최고 농도 도달 시간(Tmax)을 NONMEM 프로그 램의 spline 함수로 model-independent 약동학 파 라미터를 산출하여 각 용량별로 분석하였고, $\mathrm{AUC}$, $\mathrm{Cmax}, \mathrm{Tmax}$ 는 PKCALC 프로그램을 이용한 trapezoidal method로도 산출하여 앞의 결과와 비교하였 다. 다음에는 혈중 농도와 약력학 자료(심전도상의 $\mathrm{PQ}$ 또는 $\mathrm{QT}$ 간격)를 동시에 도시하여 농도-효과 관 계를 분석한 후에, spline 함수로부터 얻어진 개인별 예측 농도와 약력학 자료로부터 mixed-effect modeling을 하여 약력학적 파라미터를 산출하였다. Spline 함수는 다음과 같은 piece-wise polynomial 로서 ${ }^{7)}$ point 사이를 다항식으로 연결하여 줌으로써 nonparametric한 방법으로 약동학적 파라미터를 산출 하고, 나아가 경시적 농도를 예측함으로써 model-independent 약동학/약력학 modeling 을 가능케 한다 ${ }^{8,9)}$.

$$
P P(x)=P[i](x) \text { for } b[i] \leq x<b[i+1] \text {; }
$$

$$
\begin{gathered}
\mathrm{b}[\mathrm{i}](\mathrm{i}=1, \ldots, \mathrm{I})=\text { breakpoints } \\
\mathrm{P}(x)=\mathrm{a}_{0}+\mathrm{a}_{1} x+\ldots+\mathrm{a}_{\mathrm{k}-1} x^{k-1} \quad\left(\mathrm{a}_{0}, \mathrm{a}_{1}, \ldots \text { 은 상수 }\right)
\end{gathered}
$$

한 다항식의 차수 $(k)$ 는 $[x$ 의 최대차수 +1$]$ 이므로, spline을 정의함에 있어서 차수 및 breakpoints의 개 수(I)와 위치를 정하면 된다.

약력학 modeling은 linear model을 사용하였는데, spline 함수로부터 예측한 개인별 시간-농도 자료 및 심전도상 $\mathrm{PQ}$ 간격 변화를 이용하여 direct link model에 의한 mixed effect modeling을 하였다. Direct link model은 혈중농도 compartment와 effect compartment 사이에 effect site concentration 의 compartment를 가정하며, 다음 식과 같은 $\mathrm{k}_{\mathrm{eo}}$ (equilibrium 상수)를 link 파라미터로써 예측한다.

$$
\begin{gathered}
\frac{d C e}{d t}=k e o \cdot(C-C e) \\
(\mathrm{C}=\text { concentration(plasma }), \\
\mathrm{Ce}=\text { effect site concentration })
\end{gathered}
$$

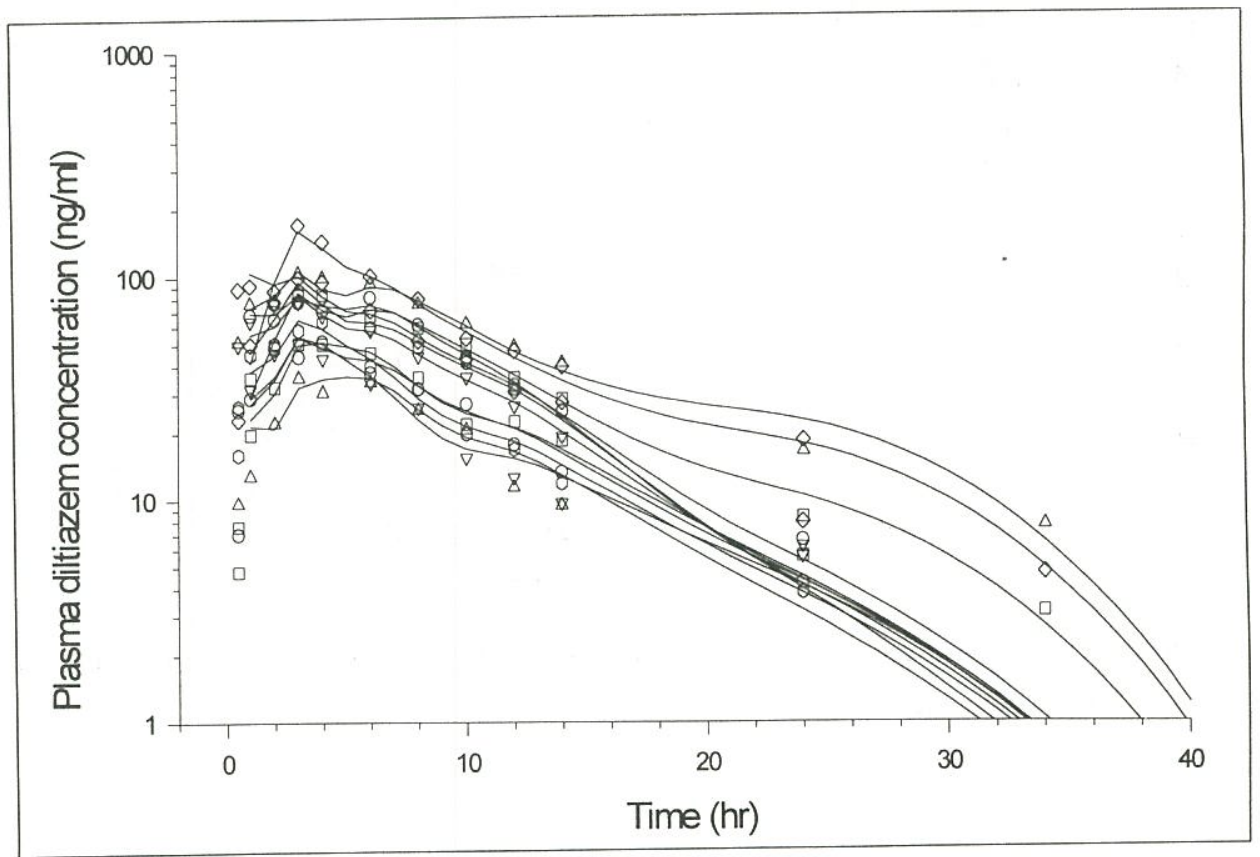

Fig. 1. Observed plasma drug concentrations(symbols) vs. spline function curves in group A(90mg). 
- 유경상 등 : 이중 최고농도를 보이는 서방형 제제의 비모수적 약동학/약력학적 분석 -

\section{연 구 결 과}

서방형 diltiazem $90 \mathrm{mg}$ 제형 투여 후의 혈중 농도 변화 및 해당 spline 곡선은 Fig. 1과 같다. 소수의 피험자에서 투약 직후에 작은 peak를 보였으나 대체 로 투약 후 3 시간 경에 단일 peak 및 그 이후의 단상 성(monophasic) 농도 감소를 보였다. $180 \mathrm{mg}$ 제형 투여 후의 혈중 농도 변화 및 해당 spline 곡선(Fig. 2)은 대부분의 피험자에서 투약 직후에 첫 peak를 보이면서 투약 후 약 8시간 경에 더 높은 농도의 peak를 보였다. $90 \mathrm{mg}$ 제형 투여군에서 spline 곡선 으로부터 산출한 약동학적 파라미터와 trapezoidal rule로부터 계산한 파라미터 비교시 서로 잘 일치하는
경향을 보였다(Table 1). $180 \mathrm{mg}$ 제형 투여군의 약 동학적 파라미터 (Table 2)는 마찬가지로 두 가지 방 법에 의한 결과가 유사한 경향을 보였다.

혈중 농도와 심전도상의 $\mathrm{PQ}$ 또는 $\mathrm{QT}$ 간격을 도시 하여 분석한 결과, $\mathrm{QT}$ 간격은 두 가지 용량에서 공히 농도에 따른 상관관계를 보이지 않았다. $\mathrm{PQ}$ 간격은 $90 \mathrm{mg}$ 용량군에서는 농도와 상관관계를 보이지 않고 $180 \mathrm{mg}$ 용량군에서만 상관관계를 보였는데, 일정한 hysteresis 또는 proteresis 양상은 보이지 않았다 (Fig. 3). $180 \mathrm{mg}$ 제형군의 혈중 농도 및 심전도 $\mathrm{PQ}$ 간격을 direct link 약동학/약력학 modeling한 결과 linear model이 적합하였으며, 그 파라미터는 Table 3 과 같다.

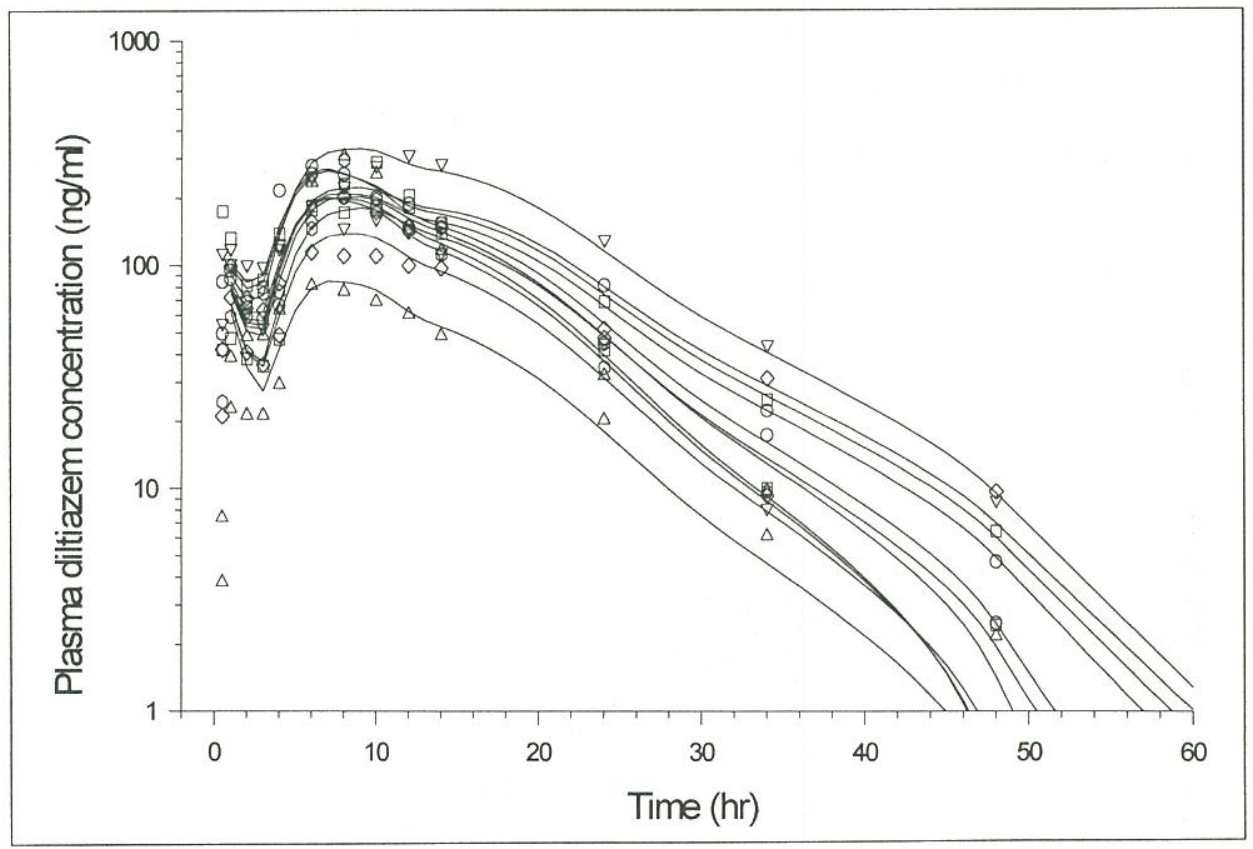

Fig. 2. Observed plasma drug concentrations(symbols) vs. spline function curves in group $\mathrm{B}(180 \mathrm{mg})$. 
- K.S. Yu, et al. : Nonparametric PK/PD analysis of controlled-release formulations showing double peak concentrations -

Table 1. Pharmacokinetic parameters for group A(90 mg) calculated from the spline function curve (left side) and by the trapezoidal rule (right side)

\begin{tabular}{ccccccc}
\hline \multirow{2}{*}{ ID code } & \multicolumn{2}{c}{$\begin{array}{c}\text { AUC } \\
{[\mathrm{ng} \cdot \mathrm{hr} / \mathrm{ml}]}\end{array}$} & \multicolumn{2}{c}{$\begin{array}{c}\text { Cmax } \\
{[\mathrm{ng} / \mathrm{ml}]}\end{array}$} & \multicolumn{2}{c}{$\begin{array}{c}\text { Tmax } \\
{[\mathrm{hr}]}\end{array}$} \\
\hline \hline & spline & trapezoidal & spline & trapezoidal & spline & trapezoidal \\
\hline A1 & 902 & 951.44 & 82.4 & 81.51 & 3.2 & 6 \\
A2 & 574 & 616.87 & 52.9 & 50.91 & 3.5 & 3 \\
A3 & 429 & 366.01 & 36.4 & 35.68 & 5.3 & 3 \\
A4 & 807 & 845.50 & 83.2 & 78.19 & 3.1 & 3 \\
A5 & 1000 & 1109.37 & 108 & 99.63 & 1.2 & 3 \\
A6 & 846 & 959.74 & 96.0 & 84.77 & 3.1 & 3 \\
A7 & 571 & 593.22 & 55.0 & 51.73 & 3.2 & 4 \\
A8 & 983 & 1012.61 & 86.4 & 84.10 & 3.1 & 4 \\
A9 & 1450 & 1511.81 & 108 & 104.90 & 3.1 & 3 \\
A10 & 495 & 507.61 & 55.7 & 51.04 & 3.3 & 3 \\
A11 & 1460 & 1579.17 & 164 & 171.58 & 3.1 & 3 \\
A12 & 580 & 579.08 & 65.9 & 63.60 & 3.2 & 4 \\
Mean & 841 & 886.04 & 82.8 & 79.80 & 3.2 & 3.50 \\
CV(\%) & 41.0 & 43.3 & 41.3 & 45.0 & 27.6 & 25.8 \\
\hline
\end{tabular}

$\mathrm{CV}=$ coefficient of variation

Table 2. Pharmacokinetic parameters for group B(180mg) calculated from the spline function curve (left) and by the trapezoidal rule (right)

\begin{tabular}{ccccccc}
\hline \multirow{2}{*}{ ID code } & \multicolumn{2}{c}{$\begin{array}{c}\text { AUC } \\
{[\mathrm{ng} \cdot \mathrm{hr} / \mathrm{ml}]}\end{array}$} & \multicolumn{2}{c}{$\begin{array}{c}\mathrm{Cmax} \\
{[\mathrm{ng} / \mathrm{ml}]}\end{array}$} & \multicolumn{2}{c}{$\begin{array}{c}\text { Tmax } \\
{[\mathrm{hr}]}\end{array}$} \\
\hline \hline & spline & trapezoidal & spline & trapezoidal & spline & trapezoidal \\
\hline B1 & 4000 & 4051.99 & 273 & 280.00 & 6.8 & 6 \\
B2 & 3010 & 3045.43 & 182 & 185.40 & 9.2 & 6 \\
B3 & 3260 & 3310.24 & 204 & 310.05 & 8.7 & 8 \\
B4 & 2930 & 3060.39 & 202 & 249.56 & 7.0 & 6 \\
B5 & 4310 & 3691.52 & 224 & 204.35 & 8.8 & 8 \\
B6 & 3020 & 3036.57 & 203 & 296.80 & 7.3 & 8 \\
B8 & 3810 & 3957.98 & 211 & 257.82 & 7.8 & 6 \\
B9 & 4490 & 4377.10 & 267 & 289.65 & 6.9 & 10 \\
B10 & 1360 & 1279.81 & 85.6 & 81.62 & 7.3 & 6 \\
B11 & 6260 & 6260.28 & 334 & 314.39 & 8.9 & 12 \\
B12 & 2210 & 2287.41 & 139 & 115.00 & 8.6 & 6 \\
Mean & 3514 & 3487.15 & 211 & 234.97 & 7.9 & 7.45 \\
CV(\%) & 36.8 & 36.3 & 31.5 & 33.7 & 11.5 & 27.1 \\
\hline
\end{tabular}

$\mathrm{CV}=$ coefficient of variation

*Subject \#7 dropped out before this dose 
- 유경상 등 : 이중 최고농도를 보이는 서방형 제제의 비모수적 약동학/약력학적 분석 -

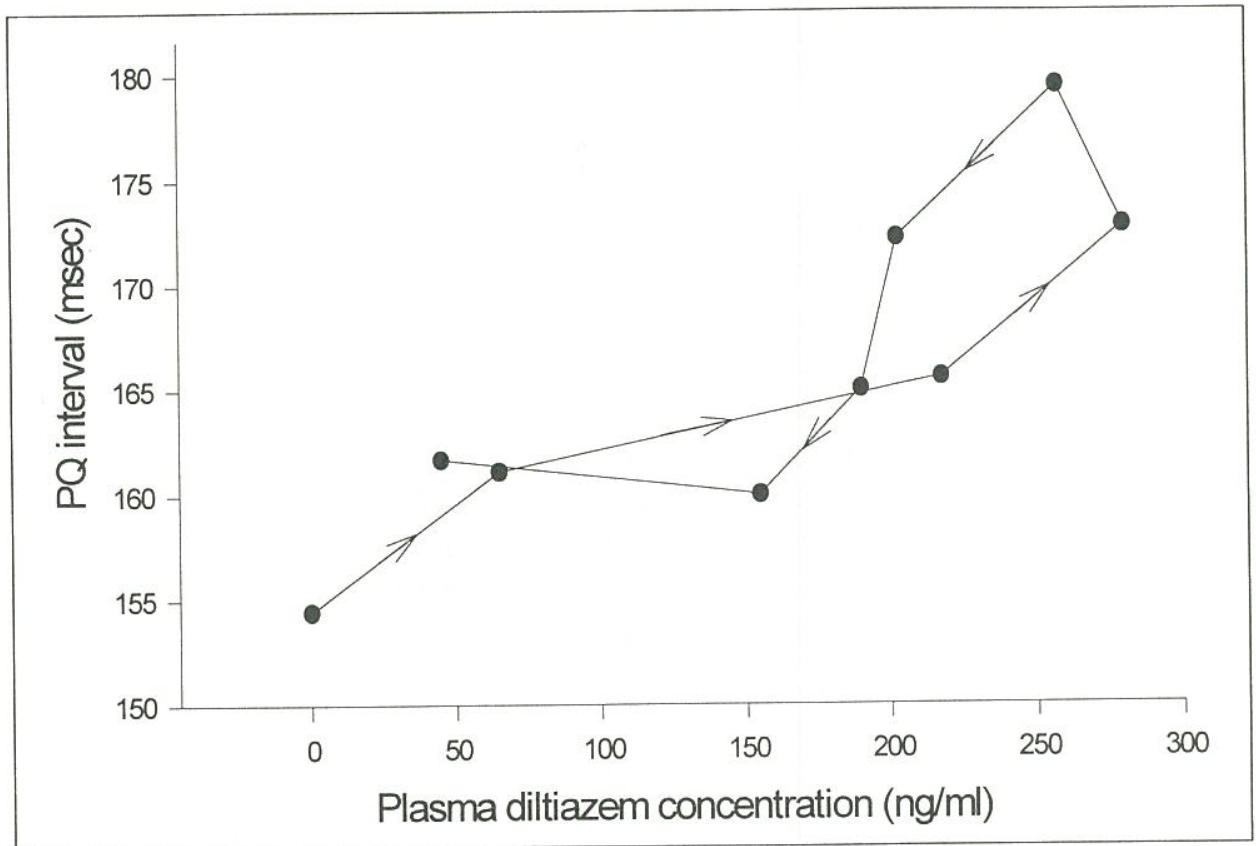

Fig. 3. Representative plasma diltiazem concentration-effect(PQ interval change) curve (in subject \#1) after test formulation $180 \mathrm{mg}$ oral administration.

Table 3. Results of direct link mixed effect PK/PD modeling(plasma diltiazem concentrations$\mathrm{PQ}$ intervals ; linear pharmacodynamic model)

\begin{tabular}{cccc}
\hline & $\mathrm{Keo}\left[\mathrm{hr}^{-1}\right]$ & Slope $[\mathrm{msec} \cdot \mathrm{mL} / \mathrm{ng}]$ & Intercept $[\mathrm{msec}]$ \\
\hline \hline $\begin{array}{c}180 \mathrm{mg} \\
\text { group }\end{array}$ & 4.47 & 0.0792 & 0.358 \\
\hline
\end{tabular}

keo $=$ equilibrium constant

\section{고 안}

본 연구에서 spline function으로부터 얻은 약동학 적 파라미터들은 기존의 trapezoidal rule로 산출한 파라미터들과 잘 일치하였으며, spline function으로 부터 얻은 개인별 시간-농도 자료를 이용하여 약동학 /약력학적 모델 분석을 하였다. 따라서 통상적인 compartment model을 적용할 수 없는 서방형 제제 등의 농도 자료를 이용하여 약동학/약력학 모델 분석 을 하고자 할 때 이러한 spline function을 이용한 방 법이 유용하게 쓰일 수 있으며, spline function을 이
용하여 약동학적 파라미터를 산출하면 기존 방법에 의 한 결과와 차이를 보이지 않으면서 곡선을 수식으로 표현하여 측정하지 않은 시간대의 농도를 예측할 수 있는 장점을 내포하고 있다.

Diltiazem의 혈장 농도와 심전도 상의 변화를 관찰 하는 데 있어서 $180 \mathrm{mg}$ 용량군과는 달리 $90 \mathrm{mg}$ 용량 군에서는 $\mathrm{PQ}$ 간격과 혈장 농도 사이에 상관 관계를 관찰할 수 없었던 이유는 상대적으로 낮은 $\mathrm{Cmax}$ 로 인하여 $\mathrm{PQ}$ 간격의 변화가 적었던 것과, 빠른 $\mathrm{Tmax}$ 와 짧은 작용 시간에 비하여 심전도 측정 간격이 상대 적으로 길었기 때문인 것으로 사료된다. 
- K.S. Yu, et al. : Nonparametric PK/PD analysis of controlled-release formulations showing double peak concentrations -

최근 기존 약물의 서방 제형을 개발하여 약물의 임 상적 효용성과 부가가치를 높이고자 하는 시도가 많이 이루어지고 있으나 이를 과학적, 객관적으로 평가하기 위한 방법에는 다소 제한점이 있었으며 특히 통상적인 약동학 모델로 분석이 어렵거나 개체별 약동학 변이가 큰 경우는 더욱 그러하였다. 최근 spline 함수 등을 이용한 nonparametric 방법의 적용이 개발되어 약동 학/약력학 modeling 분야에 응용되고 있으며 mixed effect model을 이용한 방법도 그 응용의 분야를 넓 히고 있다. 이러한 방법론은 활발하게 서방형이나 patch 제형의 특성 파악과 분석에 적용될 것으로 전 망된다.

Mixed effect modeling은 clinical drug study에 서 얻은 자료를 분석하는 방법으로써 측정된 효과 (fixed effects) 및 설명할 수 없는 개체간(intersubject) 및 개체내(intrasubject) 효과(random effects)를 동시에 고려하여 modeling하는 분석법이 며, 집단 약동학 (population pharmacokinetics) 자 료 분석 및 파라미터 산출에 이용된다 ${ }^{10)}$.

Nonparametric 약동학/약력학 분석법은 model 을 가정하지 않고 시행하는 분석법으로서 기존의 parametric 분석법과 상호 보완 관계에 있다. Parametric 분석법은 적은 수의 자료로써 의미 있는 파라미터 와 그 파라미터 예측치의 정밀도(precision)를 구할 수 있으므로 model을 설정하여 low variance prediction을 하고자 할 때 이용될 수 있다. Nonparametric 분석법은 parametric 분석법에 비하여 상대 적으로 low bias prediction을 할 수 있으므로 많은 자료를 가지고 그것을 설명하기 위한 model을 얻고자 할 때 사용할 수 있고, 또한 본 예와 같이 단순 compartmental model에는 맞지 않는 혈중농도 양상 분 석에 이용할 수 있다 ${ }^{11}$.

본 연구에서 검토한 spline 함수에 의한 nonparametric 약동학 분석과 mixed effect modeling은 각종 서방형 제제의 평가, patch 제형의 평가, 약동학적 변이가 큰 약물의 평가, 집단 약동학적 평가 및 약물의 약동학/약력학 modeling에 응용이 가능한
연구방법론으로 다양한 약물의 약동학 및 약력학 분석 에 이용될 수 있을 것으로 사료된다.

\section{요 약}

연구배경 :

본 연구는 반감기가 짧은 칼슘차단제인 diltiazem 의 개발 중인 서방형 제제를 원형 약물로 하여 이중 peak 농도를 보이는 약물의 약동학 분석에 spline 함 수와 mixed effect model을 이용한 nonparametric 약동학/약력학 모델 분석법을 검토하였다.

방 법:

12 명의 건강한 자원자를 대상으로 시험제제 $90 \mathrm{mg}$ 및 $180 \mathrm{mg}$ 캡슐을 각각 1 주 간격으로 경구 투여 후 48 시간까지 혈장 농도 및 심전도상의 변화를 관찰하 였다. Diltiazem의 혈장 농도는 HPLC(high performance liquid chromatography)로 측정하였으 며, 심전도 lead II 상의 $\mathrm{PQ}$ 및 QT 간격의 변화는 $\mathrm{AD}$ 변환기와 심전도 분석 프로그램을 이용하여 분석 하였다. 약동학적 파라미터는 spline 함수를 이용하여 산출하였으며 trapezoidal rule을 이용하여 계산된 파 라미터와 비교하였다. 약력학적 파라미터는 nonparametric 방법으로 mixed-effect modeling을 하여 산출하였다.

결 과:

$90 \mathrm{mg}$ 제형 투여 후 시간에 따른 혈장 농도는 투약 후 3 시간 경의 단일 peak와 이후의 monophasic decay 양상을 보였으며, $180 \mathrm{mg}$ 제형에서는 각각 투 약 직후 및 8 시간 경에 이중 peak를 보였다. Spline 함수를 이용하여 산출한 약동학적 파라미터는 trapezoidal rule을 이용하여 계산한 파라미터와 비슷하였 다. 혈중 농도와 $\mathrm{PQ}$ 간격의 약동학/약력학 modeling은 linear model을 이용하였는데 그 결과 $180 \mathrm{mg}$ 군에서 $\mathrm{keo}=4.47 \mathrm{hr}-1$, slope $=0.0792 \mathrm{msec} \cdot \mathrm{ml} /$ $\mathrm{ng}$, intercept $=0.358 \mathrm{msec}$ 이었다.

결 론:

본 연구에서 검토한 spline 함수에 의한 nonpar- 
- 유경상 등 : 이중 최고농도를 보이는 서방형 제제의 비모수적 약동학/약력학적 분석 -

ametric 약동학 분석과 mixed effect modeling은 각종 서방형제제의 평가, patch 제형의 평가, 약동학 적 변이가 큰 약물의 평가, 집단약동학적 평가 및 약 물의 약동학/약력학 modeling에 응용이 가능한 연구 방법론으로 다양한 약물의 약동학 및 약력학 분석에 이용될 수 있을 것으로 사료된다.

\section{참 고 문 헌}

1. Murata K, Yamahara H, Kobayashi M, et al. Pharmacokinetics of an oral sustained-release diltiazem preparation. I Pharm Sci $1989 ; 78(11): 960-963$

2. Lind L, Lithell H, Johansson CG, et al. Electrocardiographic changes during antihypertensive treatment with diltiazem in relation to the achieved serum levels of the drug. Scand J Clin Lab Invest 1994 ; 54 :33740

3. Funck-Brentano C, Jaillon P. Rate-corrected $Q T$ interval:Techniques and limitations. Am J Cardiol 1993; $72: 17 B-22 B$

4. Murray A, McLaughlin NB, Bourke JP. Errors in manual measurement of QT intervals. $\mathrm{Br}$ Heart J 1994; 71 : 386-390

5. Molnar J, Weiss J, Zhang F, et al. Evaluation of five QT correction formulas using a software
- assisted method of continuous QT measurement from 24-hour holter recordings. Am J Cardiol 1996; 78:920-926

6. Montamat SC, Abernethy DR, Mitchell JR. High-performance liquid chromatographic determination of diltiazem and its major metabolites, $N$-monodemethyldiltiazem and desacetyldiltiazem, in plasma. JChromatogr $1987 ; 415: 203-207$

7. DeBoor C. A practical guide to splines. Springer-Verlag, New York, 1978

8. Fattinger KE, Verotta D. A nonparametric subject-specific population method for deconvolution:I. Description, internal validation, and real data examples. J Pharmacokinet Biopharm $1995 ; 23(6): 581-610$

9. Verotta D. Longitudinal splines. Technical report \#36. Department of Biostatis-tics, University of California, Sanfran-cisco, 1993.

10. Boeckmann AJ, Sheiner LB, Beal SL. NONMEM users guide part $V$ introductory guide. NONMEM Project Group, University of California, San Francisco, Jul 1991.

11. Sheiner LB, Rowland M. Workshop on advanced methods in pharmacokinetics and pharmacodynamics. San Francisco, California. Apr 1997. 